Southern Illinois University Edwardsville SPARK

SIUE Faculty Research, Scholarship, and Creative Activity

2016

\title{
The Impact of Traffic Incident Locations on a Metropolitan Evacuation
}

\author{
Karzan Bahaaldin \\ Ryan N. Fries \\ rfries@siue.edu \\ Michael R. Williamson \\ Indiana State University \\ Mashrur Chowdhury \\ Clemson University
}

Follow this and additional works at: http://spark.siue.edu/siue_fac

Part of the Civil Engineering Commons

\section{Recommended Citation}

Bahaaldin, Karzan; Fries, Ryan N.; Williamson, Michael R.; and Chowdhury, Mashrur, "The Impact of Traffic Incident Locations on a Metropolitan Evacuation" (2016). SIUE Faculty Research, Scholarship, and Creative Activity. 63.

http://spark.siue.edu/siue_fac/63

This Article is brought to you for free and open access by SPARK. It has been accepted for inclusion in SIUE Faculty Research, Scholarship, and Creative Activity by an authorized administrator of SPARK. For more information, please contact magrase@siue.edu. 


\title{
The Impact of Traffic Incident Locations on a Metropolitan Evacuation
}

\author{
Karzan Bahaaldin, P.E. \\ Ph.D. Candidate, Southern Illinois \\ University Edwardsville
}

Michael Williamson, Ph.D. Assistant Professor, Indiana State University

\author{
Ryan Fries, Ph.D., P.E. \\ Associate Professor, Southern Illinois \\ University Edwardsville \\ rfries@siue.edu \\ (Corresponding Author)
}

Mashrur A. Chowdhury, Ph.D., P.E.
Mays Professor, Glenn Department of
Civil Engineering, Clemson University

\begin{abstract}
Modeling emergency evacuations can help engineers, planners, and emergency managers identify the approximate time it would take for evacuees to leave a disaster area. Unfortunately, many evacuation studies do not account for traffic incidents. This study examined the effect of traffic incidents during a no notice emergency evacuation in the eastern St. Louis metropolitan area road network. The roadway network was modeled using traffic micro-simulation software VISSIM, which utilized the expected traffic volumes that were determined by the regional planning agency, and guided by input from the transportation engineers at the Illinois Department of Transportation (IDOT). Because traffic speeds are expected to be low during such a high-volume event, this study considered only minor incidents. Incident locations were selected based on historical data. The results suggest that minor traffic incidents occurring upstream of key bottlenecks created no significant change in delay or evacuation duration. On the contrary, minor traffic incidents downstream of bottlenecks can significantly increase delay; albeit not enough to delay the duration of the entire evacuation by more than 15 minutes. Thus, during no notice emergency evacuations, traffic managers could prioritize available traffic incident management resources accordingly.
\end{abstract}

Keywords: Evacuation, Traffic incidents, Traffic simulation.

\section{Introduction}

The main purpose of each evacuation plan is to help prepare for the process of moving people from an affected area to a safe location, in the shortest possible time. The traffic volumes and roadway capacity are critical to achieving this goal. The evacuation process is influenced by many factors that affect the required time to evacuate. The influential factors can be divided into two types, uncontrolled and controlled. Weather and its impact on road conditions is uncontrollable, but the duration of traffic incidents are sometimes controllable.

Traffic incidents during evacuations may include vehicles overheating, having flat tires, running out of gas, and/or crashing. Incidents should be mitigated as quickly as possible to keep traffic flowing by reopening lanes to preserve the capacity of the roadway. Staging of 
emergency personnel along the route is vital for reducing clearance times and providing necessary medical care to those that are injured, because accessing incidents can be difficult during times of evacuation (Wolshon 2009). This study evaluated the locations where incidents occurred historically and identified their influence during an evacuation. These impacts could include the evacuation clearance time and motorist delay, in addition to the safety of the evacuees and the individuals involved in the traffic incident.

\section{Previous Work}

A literature review was conducted to identify previous knowledge on evacuations, specifically which factors would affect the reliability of simulation model results. Previous evacuation research has focused on factors such as traffic incidents, communication issues, and capacity improvements needed to serve evacuation demands.

\subsection{Traffic Incidents during Evacuations}

A study by Chen was conducted to measure the time required for evacuation, where the micro-simulation software Paramics was used. The model tested three different networks (grid, ring and real) for simultaneous or staged evacuations, in which the driver aggressiveness was distributed from low to high. Although the impacts of traffic incidents were noted as an important factor, they were excluded from the simulation process. This study revealed that because staged evacuations cause less congestion on the roadways, the possibility of traffic incidents decreased [1]. In contrast, others have subsequently noted that panicked behavior will likely result in more traffic incidents [2]. Further, evacuation staging of resources is not feasible before no-notice evacuations.

Other previous work has focused on the prevalence of traffic incidents during evacuations. These studies reported that crashes are much more likely during reentry rather than during evacuation [3] and that evacuations have a higher number of traffic incidents than normal congested operations [4]. A study of two regions found that traffic incidents were predicted to increase evacuation duration by 7.2 to 8 percent. In particular, incidents at bottlenecks caused traffic to re-route to longer routes [5]. On the contrary, other studies have found very minimal evacuation impacts due to traffic incidents [6]. These contrary results suggest a need for further investigation.

A study reviewing 50 evacuation cases found that only four traffic incidents occurred in these events ( 8 percent) [7]. Of those four incidents, three were minor or caused by vehicles running out of gas. The fourth traffic crash was related to roadways being blocked by heavy smoke, downed power lines, and abandoned vehicles. The severity of this traffic crash was not reported, but the victims subsequently lost their lives in the ensuing wildfire. Although the frequency of traffic incidents during evacuations was relatively small, the analysis revealed a statistically-significant link between the occurrence of crashes and the degradation of evacuation performance. A deeper review of this study revealed that only 45 percent of the cases were no-notice events. The fifty evacuations were selected for statistical analysis where traffic crashes were identified as having a statistically significant effect on the evacuation process at the 95 percent confidence level. Chi-squared testing indicated that traffic crashes have a strong relation to evacuation efficiency, however the relationship between hazard timing (i.e. short notice or no-notice evacuation) and traffic crashes was not found to be significant. Correlations between other variables and traffic issues were also investigated. It 
was found that traffic crashes were ranked third in traffic issues during an evacuation, surpassed only by information dissemination and roadway availability. The pertinent findings in the study were that informed citizens will evacuate more efficiently, that the availability of major roadways is vital, and that traffic incidents can impede the evacuation process [8].

Because of the perceived importance of traffic incidents during evacuations, several studies have examined specific cases. One case study evaluated urban signalized arterials and the findings suggested that only traffic incidents blocking more than one lane or located at bottlenecks will significantly increase evacuation durations [9]. Chen et al. (2009) specifically studied traffic incidents during an evacuation, focusing on those caused by rain and wind directly before a hurricane [10]. Others have included the influence of different weather conditions on the performance of the evacuation [11] as recommended by earlier work [12]. Overall, these studies provide evidence that the impact of traffic incidents should not be ignored when modeling an evacuation of any type.

In the southeastern US, the state of Georgia has declared many weather-related evacuations [13] and thus has had multiple opportunities to study and refine operations during evacuations. Their key areas of preparedness include signage, traffic flow, traveler information, and traveler assistance. Traveler assistance is of particular interest because the use of assistance programs can keep the flow of traffic more stable. Georgia uses Highway Emergency Responder Operator (HERO) vehicles to improve flow due to non-recurrent incidents during congested times and evacuations. These practices have focused towards short-notice evacuations and have not included no-notice evacuations [13].

No-notice evacuations are similarly difficult to manage. In contrast to short notice, most of the effort is focused on monitoring and responding to situations including traffic incidents. In 2006 the US Federal Highway Administration [14] recognized the need to develop methods for managing no-notice evacuations. A survey was conducted, targeting several regions often subjected to evacuations. The responding agencies identified traffic simulation as a useful tool for planning evacuations and studying the capacity. It was found that some agencies, including the Oregon Department of Transportation (DOT), use simulation to estimate evacuation times, considering emergency type, and regional population.

The use of traffic simulation models to assess the roadway performance under different conditions such as traffic incidents, driver behavior, insufficient roadway designs and weather could have been used for evacuation planning to improve the evacuation process. Traffic simulation models are commonly used for determining the roadway network operations and selecting optimum routes during an evacuation [8].

\subsection{Communicating to the Public during Evacuations}

Communication was identified as a major issue that caused backups and limited the routes chosen during the evacuation of New Orleans for Hurricane Katrina [15]. Providing resilient communication during disasters to handle the network congestion caused by larger numbers of calls by responders and victims is among the suggestions for better evacuation strategies after Hurricane Sandy. Another important issue was getting fuel trucks for supplying vehicles during and after the evacuation process which will assist in smoother evacuation and recovery by preventing stalled vehicles on the roadway that affect the evacuation process [16].

The National Highway Cooperative Research Program (NCHRP) report 525 suggests the use of automatic vehicle location (AVL), motorist feedback, and responder reports to track 
travel times during an evacuation. In turn, information is provided back to the travelers in the form of estimated travel times to safe locations that have been predetermined during the planning process. Relaying this information to the travelers in the form of radio communications and cellular phone messages has been effective to improve the evacuation process by allowing travelers to make more-informed route decisions [17].

Evacuations can be voluntary, where citizens choose to evacuate an area based on the perceived risk of some event; or mandatory, where citizens are ordered to evacuate an area due to extreme risks. Research has been conducted on the attitudes of different populations when encountering extreme events prompting evacuations, with most of the data available related to hurricane evacuations. A study in Florida [18] took survey data and found that people make a decision to evacuate or shelter in place based on the perception of the negative impact of the threat and likelihood of their residence being in harm's way. The study found that the higher the risk the more likely citizens are to evacuate.

The public perception to risk $[19,20,21]$ can be greatly influenced by the media who typically convey information pasted down from public officials or weather forecasting services. Increased media coverage during an extreme event is thought to increase the likelihood that citizens will evacuate an area due to the perceived risk associated to media coverage.

\subsection{Evacuation Road Network Capacity}

In 2006 the American Highway User's Alliance [15] developed an evacuation index for major cities in the United States. Called exit capacity, the purpose was estimating evacuation times. When applied, the index determined that the capacity of roads outside New Orleans can handle two-thirds of the evacuees in 12 hours if no issues occurred during the evacuation process, the reason being that each roadway will have a maximum capacity directly impacting the evacuation time. An in-depth study [22] on the evacuation capacity of all cities in the United States with populations over $1,000,000$ found that three factors influence an evacuation the most: exit capacity, internal traffic flow, and automobile access. Exit capacity can be summarized as the capacity of the major roadways exiting an urban area. Internal traffic flow refers to the ability of traffic to flow within the urban area to major roadways exiting the area. The last major influence on exiting capacity will be that people without access to an automobile will have greater difficulty due to their dependence on public transportation. Of the three major influences, internal traffic flow caused by bottlenecks in the network can greatly reduce capacity, some of which can be mitigated by proper signal timing or other preventative measures.

Several other evacuation studies have used mesoscopic simulation tools such as DynusT. These studies have helped to identify problematic locations during evacuations [23] and that freeway interchanges are common sources of congestion during evacuation traffic demands [24].

\subsection{Summary of Previous Work}

Previous studies on traffic incidents occurring during an evacuation do not all agree that delay increases. Overall, more research has been directed towards short-notice 
evacuations than no-notice evacuations. These previous results suggest a value in a microscopic analysis of freeway interchange operation during a no-notice evacuation, to identify if traffic incidents effect the overall evacuation.

\section{Data collection}

The study described herein required different stages of data collection. Aerial images of the area obtained from online sources and the Geography Department at Southern Illinois University Edwardsville (SIUE) were used as a background for creating the roadway network. The Stan Musial Veteran Memorial Bridge and new Chain of Rocks Canal Bridge plans were obtained from the Illinois and Missouri DOTs; IDOT and MODOT, respectively. The traffic volumes and Origin/Destination Matrices for trip generations were obtained from the East West Gateway Council of Government (EWGCOG) which is the Metropolitan Planning Organization (MPO) for St. Louis area. The data collected, their purpose in the study, and the sources are listed in Table 1.

Table 1: Data Collection Purpose and Sources

\begin{tabular}{|c|c|c|c|}
\hline Data & Purpose & Source & Remarks \\
\hline \multirow[t]{2}{*}{ Aerial Images } & Creating network & $\begin{array}{c}\text { Geographic } \\
\text { Department (SIUE) }\end{array}$ & $\begin{array}{l}\text { Used as a base for the } \\
\text { model }\end{array}$ \\
\hline & Creating network & Google Website & $\begin{array}{c}\text { Used as a base for the } \\
\text { model }\end{array}$ \\
\hline $\begin{array}{c}\text { Stan Musial Veteran } \\
\text { Bridge Plans (I-70) }\end{array}$ & $\begin{array}{c}\text { Completing the } \\
\text { network to reflect } \\
2014\end{array}$ & IDOT, MODOT & $\begin{array}{l}\text { Under construction } \\
\text { when the model was } \\
\text { developed }\end{array}$ \\
\hline $\begin{array}{l}\text { Chain of Rocks Canal } \\
\text { Bridge Plans (I-270) }\end{array}$ & $\begin{array}{c}\text { Completing the } \\
\text { network to reflect } \\
2014\end{array}$ & IDOT, MODOT & $\begin{array}{l}\text { Completed but not } \\
\text { updated in Ariel } \\
\text { images }\end{array}$ \\
\hline $\begin{array}{l}2013 \text { Traffic } \\
\text { Volumes }\end{array}$ & Model Calibration & IDOT Website & $\begin{array}{c}\text { For } 14.5 \text { mile segment } \\
\text { of } \mathrm{I}-55,70\end{array}$ \\
\hline $\begin{array}{l}\text { Traffic Signal } \\
\text { Timing }\end{array}$ & $\begin{array}{l}\text { Modeling in the } \\
\text { network }\end{array}$ & $\begin{array}{l}\text { IDOT-District } 8 \\
\text { Site Visits }\end{array}$ & Traffic Control \\
\hline Trips 0/D Matrices & $\begin{array}{l}\text { Loading the network } \\
\text { with traffic volumes } \\
\text { and destinations }\end{array}$ & EWGCOG & $\begin{array}{l}\text { Reflects the } \\
\text { evacuation volumes } \\
\text { for } 2014\end{array}$ \\
\hline Travel Times & Model Calibration & Field Data Collection & $\begin{array}{c}\text { For } 14.5 \text { mile segment } \\
\text { of } \mathrm{I}-55,70\end{array}$ \\
\hline Queue Lengths & Model Validation & Field Data Collection & Routes 157 \& 159 \\
\hline Truck Percentage & Traffic distribution & Field Data Collection & $\begin{array}{l}\text { Segments of I-55, } 70 \\
\text { and I-64 }\end{array}$ \\
\hline Incident Data & Locating the hotspots & IDOT-District 8 & Six month data \\
\hline Stop Signs & $\begin{array}{l}\text { Modeling in the } \\
\text { Network }\end{array}$ & Field Data Collection & Traffic Control \\
\hline
\end{tabular}




\section{Methods}

The researchers first built, calibrated, and validated a microscopic traffic simulation model of the Metro-East St. Louis primary routes. Next, incident data during six months of 2013 was analyzed for this road network, to identify frequent locations where minor traffic incidents occur. The simulation model was used to evaluate the impact of these traffic incidents during an evacuation scenario. The following subsections describe these steps in detail.

\subsection{Model Building}

The microscopic vehicle traffic simulation software VISSIM 5.4 was used for building the model for this study. Studies considered VISSIM and Paramics as appropriate for modeling large-scale evacuations [25]. VISSIM was selected over Paramics because of its ability to model detailed vehicle and driver characteristics and the familiarity of the researchers. Driver behavior modeling is controlled by various parameters with the capability of modeling different segments or types of roadways with multiple driver behaviors. The model primarily consisted of freeways and state routes in the Metro-East of the St. Louis Metropolitan area, just east of the Mississippi River in Illinois, United States.

The finished model included 522 links, 973 link connectors, 707 nodes, 246 zones/gateways, 38 traffic lights, and 191 priority rules (for stop signs, etc.). Overall, the network included 497 miles of roadway, totaling 995 lane-miles. The routes included Interstates 55, 64, 70, 255, and 270; Illinois State Routes 3, 4, 11, 15; and U.S. 40. The geometry for these routes was created by overlaying high-quality aerial imagery to scale within VISSIM, similar to [26]. The researchers obtained and overlaid plans for construction projects that would be complete by the base year of 2014 because aerial images were not yet available. These included the new Stan Musial Veterans Memorial Bridge, carrying I-70 over the Mississippi River [27], and the reconstructed I-270 Chain of Rocks Canal Bridge. Details of the sources for this information are shown in Table 1.

The East West Gateway Council of Governments partnered with the researcher team to estimate the evacuation demands for the year 2014. The East West Gateway Council of Governments has leveraged CUBE software to build a tour-based forecasting model including geographic information systems (GIS) data. This model has been continually refined over the past ten years and proved a valuable resource for predicting the evacuation travel demands for the 2.8-million residents [28] of the St. Louis region. Previous studies have noted the value of using GIS to support macroscopic models in determining the travel demands during evacuations [29]. In contrast, our method applied GIS traffic volume data to a microscopic model to simulate the behavior of the demands that were predicted by East West Gateway's travel demand forecasting model. The prediction of these volumes assumed that employees within the evacuation zone would travel towards home and residents in the evacuation zone would proceed towards a shelter in their state of residence. Because this study focused on a no-notice evacuation, the departure times were not as dispersed as short-notice evacuations. The researchers used a loading profile with all traffic beginning their journey within one hour.

The researchers acknowledge that not all travelers will follow these predictions. Although previous research notes the impact of families seeking each other out in

efforts to evacuate together [30] and addressing responsibility for picking-up children [31], it is unclear if these assertions hold true during a no-notice evacuation. Instead, 
the researchers assumed that the demand on the river crossings between St. Louis, Missouri and Illinois would not be significantly affected because the duration of the evacuation greatly exceeded the time expected for families to regroup. The VISSIM model zones were numbered according to the extracted network from the East West Gateway so the origin-destination matrices could be applied more-directly.

Modeling a large-scale evacuation using a microscopic model involves certain assumptions. In this study, researchers assumed that all inter-regional traffic (particularly external-to-external trips) would be informed about the evacuation event and directed to choose alternate routes to traverse the region 10 minutes after the evacuation started. This time was chosen to match the timeliness requirement of US regulation 23 CFR Part 511 [32]. Additionally, the model accounted for the rerouting of in-bound inter-regional traffic as recommended in the region's evacuation plans. Because this study focused on a no-notice evacuation, contraflow was not a feasible operation due to the time constraints on law enforcement and traffic operations personnel.

\subsection{Model Convergence, Calibration, and Validation}

The researchers leveraged the VISSIM dynamic assignment feature to assign vehicles to optimum routes. In the area modeled, there were limited high-capacity routes available for evacuation. Although local agencies did not plan to restrict exiting vehicle flow from the interstate, researchers assumed traffic would avoid low-capacity local roads, as suggested by [33]. The primary focus of convergence was arterial route Illinois 15 from the city of East St. Louis to Interstate 255.

The researchers calibrated and validated the driver behavior in the model using an approach and parameters well-established by other studies [34,35]. Due to the ongoing construction projects in the region, only certain portions of the interstate network could be used to calibrate the model to observed St. Louis driver behavior and speeds. The extracted 14.5-mile section was along I-55/70/US50 between IL203 and IL159, as shown in Figure 1. The researchers assumed it was a valid measure of regional driver behavior and speed distributions because of its location in the center of the road network modeled. The model included only routes within the bounds noted in Figure 1. 


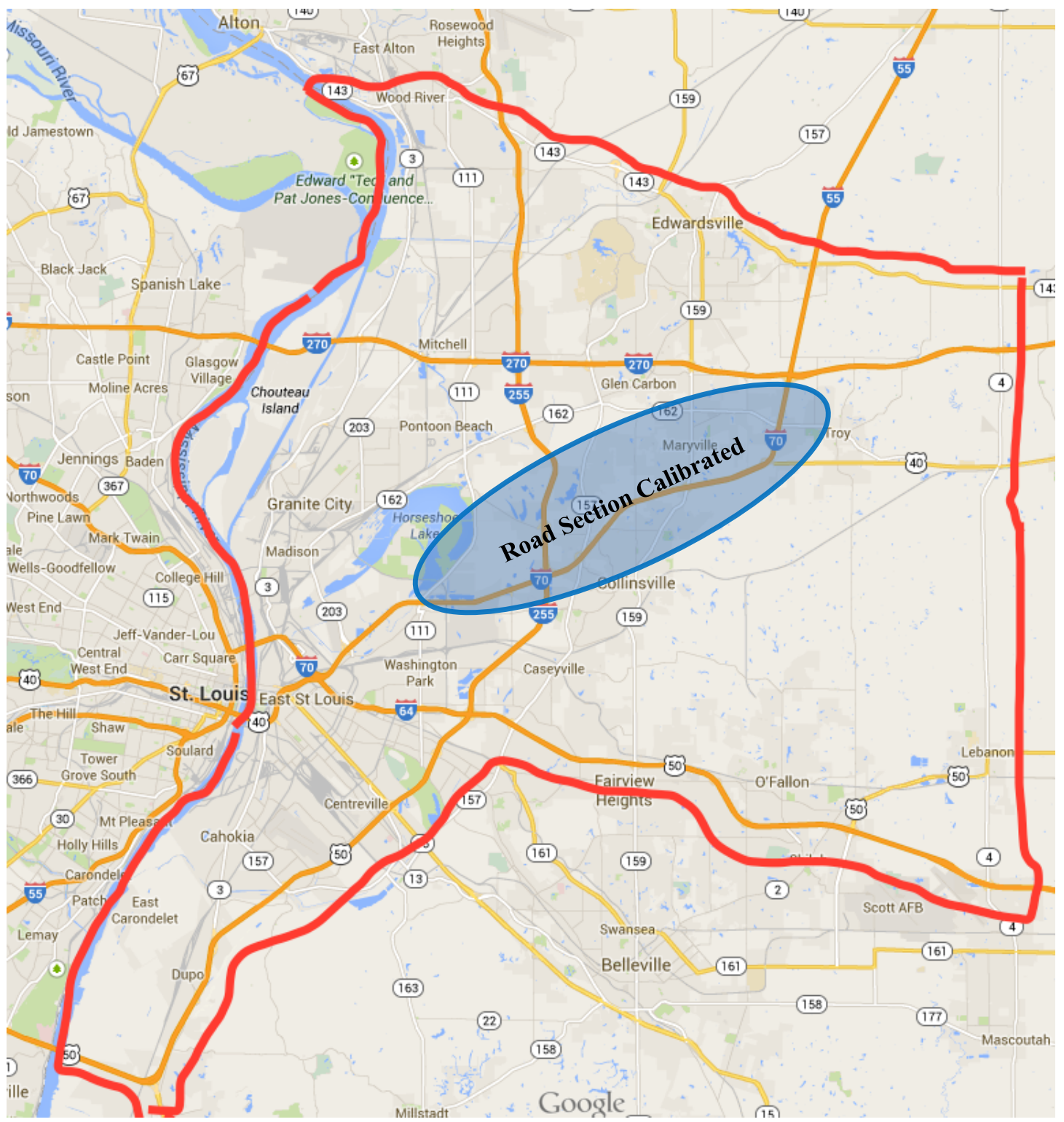

Figure 1: Location of modeled network (Adapted from Google Maps)

The driver aggressiveness was modeled in VISSIM by defining the characteristics of the driver during simulation. The initial driver behaviors on freeway links were defined in VISSIM's Wiedemann 99 model for this study because it was more suitable for freeway segments. Driver behaviors on arterial links were defined with a modified Widemann 99. During the model calibration, researchers modified these values so that the segment travel times for PM peak hour volumes matched average PM travel times collected in the field. After running the model for more than 40 times with different combinations of variables, the travel times converged to within $\pm 1-4$ seconds $(<1 \%)$, as shown in Table 2. The calibrated car following characteristics were a standstill distance (CC0) of four feet, a headway time (CC1) of 0.7 seconds and a following variation (CC2) of seven feet. The remaining variables were kept as default Widemann 99 
because they had negligible effect on the travel time, or they were the commonly accepted in transportation research. The results of the model calibration and validation was satisfactory according to methods described by [34,35], only differing 4 seconds $(<1 \%)$ between measured and observed travel times.

When reviewing the performance of the entire simulation model, researchers identified that vehicles operating with the calibrated behaviors were not realistically merging and diverging at key bottlenecks. To address this challenge, a moreappropriate set of driver behaviors were applied at these bottlenecks, as recommended by the software developers. These parameters are shown in the right-most column of Table 2. Bottlenecks were considered as sections of the road network where capacity decreased below the upstream road segment. Examples of bottlenecks can include lane drops, weaving segments, or merges. These locations require vehicles to make lane changes, speed adjustments, and be cooperative with other drivers. A key bottleneck in the St. Louis metro-east freeway network was the tri-level interchange, where US 40, I55, I-64, and I-70 diverge, requiring more maneuvers than the upstream freeway segment.

Table 2: Driving behavior parameters used in the model

\begin{tabular}{l|c|c|}
\cline { 2 - 3 } Parameters Name & Regular Segments & Bottlenecks \\
\hline CC0 - Standstill distance (ft.) & 4.00 & 16.40 \\
\hline CC1 -Headway time (s) & 0.70 & 1.50 \\
\hline CC2 - Following variation (ft.) & 6.99 & 40.00 \\
\hline Cooperative lane change & Not Checked & Checked \\
\hline Max. Deceleration for cooperative breaking & -9.84 & -5.00 \\
\hline Safety distance reduction factor & 0.60 & 0.10 \\
\hline
\end{tabular}

\subsection{Secondary Incident Analysis}

Researchers collected traffic incident data for six months (January-June 2013) from the local IDOT District Office. Because this study focused on only the roadways in Illinois, the data was refined to include only traffic incidents that would influence the operation of Illinois roadways during an evacuation of St. Louis, MO. For example, incidents on travel lanes inbound to St. Louis were disregarded and a total of 451 incidents were reviewed. The roadways considered for the evacuation were freeways and major highways in the area, due to their higher capacities.

The historical data was sorted by incident type and by durations of less than one hour. This threshold was guided by the type of incidents observed in previous evacuation events [7] and because researchers assumed that minor crashes and stalls were more likely due to the low travel speeds in the study network during a no-notice evacuation. The researchers excluded moving operations, night work, rest area closures, roadwork and short-term utility work because these types of incidents were 
less likely to persist during evacuations. The remaining minor incidents $(n=59)$ were assumed to close one lane of traffic. The historical incident locations and their frequency are shown in Figure 2.

The top locations with the highest incident frequencies were determined to be the on the Poplar Street Bridge (PSB), on I-270 near the interchange with IL-3, and on I-55/70 near the interchange with the Martin Luther King (MLK) Bridge; as shown in Figure 2.

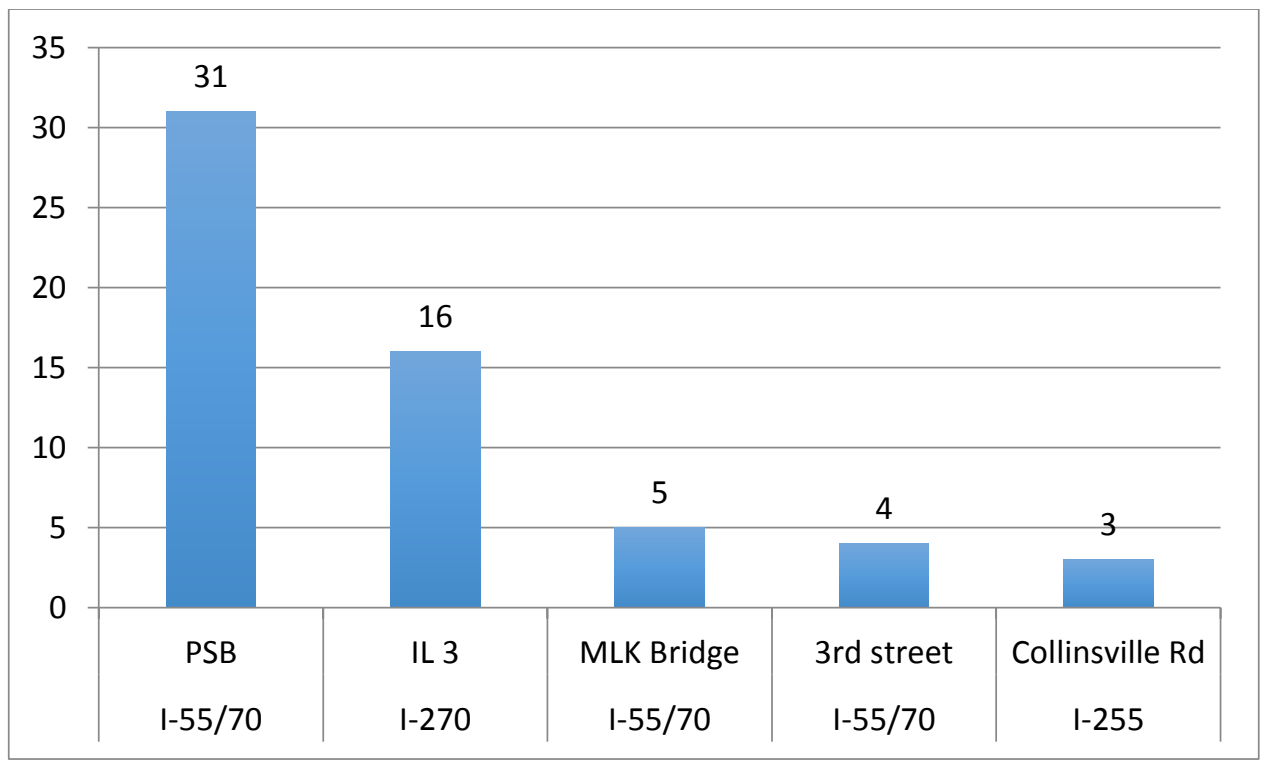

Figure 2: Minor incident locations based on frequency

Initially, researchers selected five incident durations within the limits of the actual data, randomly from 10-60 minutes. The results obtained from five simulation runs at each location suggested that the variance of durations for these secondary traffic incidents did not significantly change the duration required for the evacuation from the primary incident. After discussions with operations engineers at the Illinois Department of Transportation, researchers chose 45 minutes as an appropriate average time for a minor secondary incident to be cleared with an ongoing evacuation taking place. Henceforth, a constant duration of 45 minutes was applied at all locations. During the simulation of each scenario, researchers verified that the network gateway links had the evacuation capacity to hold all entering vehicles; therefore, capturing the delay of all vehicles.

The model used 30 minutes of simulated warm-up time for adding background traffic throughout the model, after which the evacuation incident was simulated. Secondary incidents blocked one lane of traffic starting fifteen minutes after the evacuation event. 


\section{Simulation Analysis}

The key measure of effectiveness used for the evaluation was the average delay time for the entire network. The base scenario results were compared with the incident scenarios for each of the top three high-incident locations. The results used in the comparison were the average values from 6 runs for each scenario (total of 24 simulation runs). Because VISSIM software is stochastic, some variations in the results occur between each run. Figure 3 shows the confidence bounds of the normalized evacuation delay with incidents at different locations, compared with the base scenario, with no incidents. The vertical bars represent the upper and lower bounds of the 95percent confidence intervals. If the bars overlap between two scenarios, it can be concluded that there was no statistically-significant difference in delay. The first two incidents, at the Poplar Street Bridge and near the Chain of Rocks Canal Bridge along I270, have delays that are no different from the base scenario (without incidents). Incidents at these locations are not expected to impact the total average network delay during an evacuation, compared to a scenario without incidents. In contrast, the incident at the interchange of I-55/70 and Illinois Route 203, just over one mile downstream of a bottleneck, had a significant effect. The percent differences are shown instead of the total delay (minutes) for security purposes.

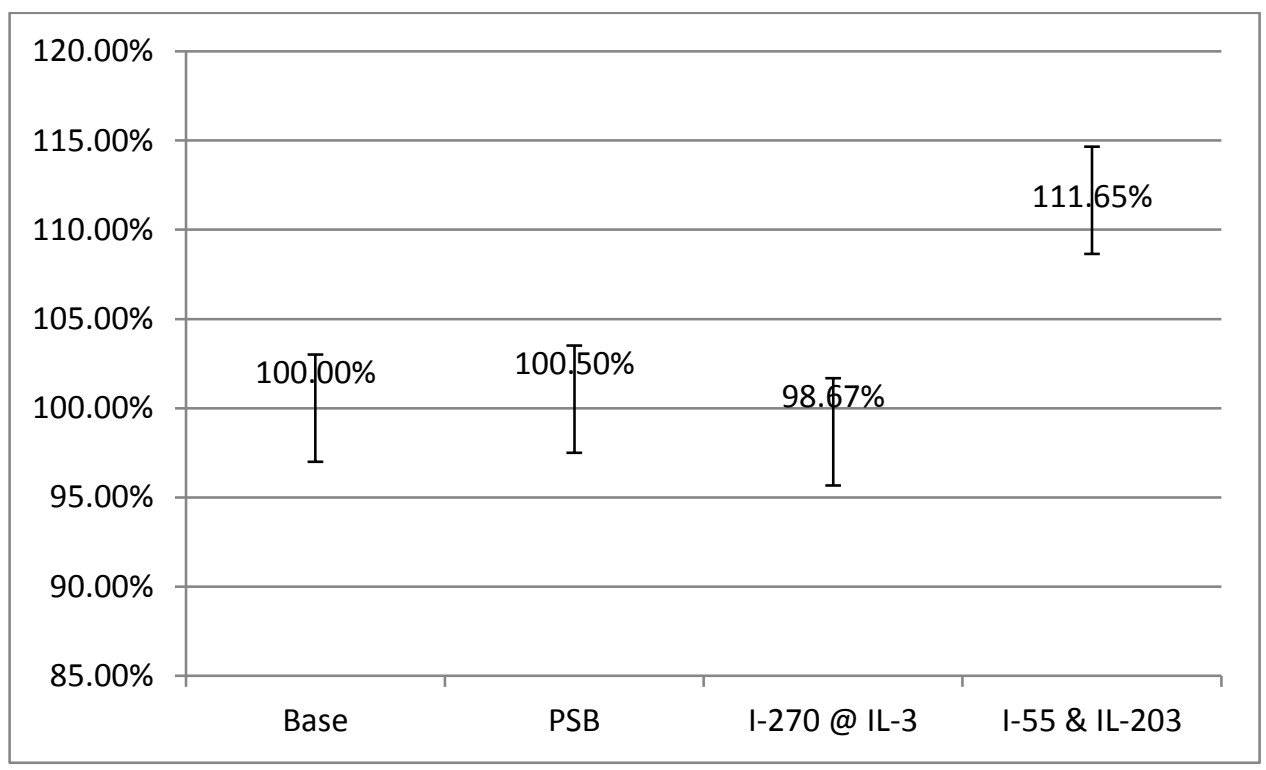

Figure 3: Incident impact by location

Although Figure 3 graphically displays the difference in the means and dispersions, the researchers also conducted a t-test of the sample means to confirm that more could not be learned from the incident locations at the PSB and at I270 at IL3. From the findings the $\mathrm{p}$-values for the sample mean delays supported the conclusions drawn from Figure 3.

After an investigation of the road network surrounding each of these incident locations, the researchers identified that the Poplar Street Bridge and the Chain of Rocks Canal Bridge (I-270) were upstream of bottlenecks in the road network. These facilities are saturated with vehicle traffic during St. Louis PM peak hours, when traffic 
is leaving the city. Thus, we interpret these findings to predict that incidents within a mile upstream of key bottlenecks do not significantly change the traffic delay during a no-notice evacuation. These findings agree with previous traffic flow research $[36,37]$ that minor traffic incidents upstream of bottlenecks cause insignificant impact.

On the contrary, previous research focusing on evacuation along arterial routes with traffic signals suggested that incidents at bottlenecks can significantly increase the evacuation duration [9]. Several others [7,5] also note that traffic incidents do significantly influence evacuation operations. Thus, the findings herein validate previous traffic flow theory research for an evacuation scenario and clarify other evacuation research by noting the importance of incident location with respect to bottlenecks.

To gain further insight into the simulation results, the researchers evaluated the average network delays for each 15 -minute period. Figure 4 displays this information for the end part of the evacuation, in 15 minutes intervals and normalized by dividing over the base scenario delay during each interval. This evidence suggests that the network delay during an evacuation was no different for any of the scenarios during the first several hours. Towards the end of the evacuation simulation, these differences indicate that more vehicles were still navigating congested parts of the network. It should be noted that none of the scenarios increased the duration of the evacuation beyond the same 15-minute time interval. Thus none of the simulated incidents caused a large change (>1/4 hour) in the overall evacuation duration.

When evaluating the information shown in Figure 4, also note that the scenario evaluating an incident at the interchange of I-270 and Illinois Route 3 (triangles in Figure 4) predicted negative delay because all data has been normalized in comparison to the base scenario. Negative percentages indicate lower average delays during those time intervals, compared to the base scenario. Because these delay differences were not statistically significant, researchers suggest they might be caused by the stochastic nature of the software. 


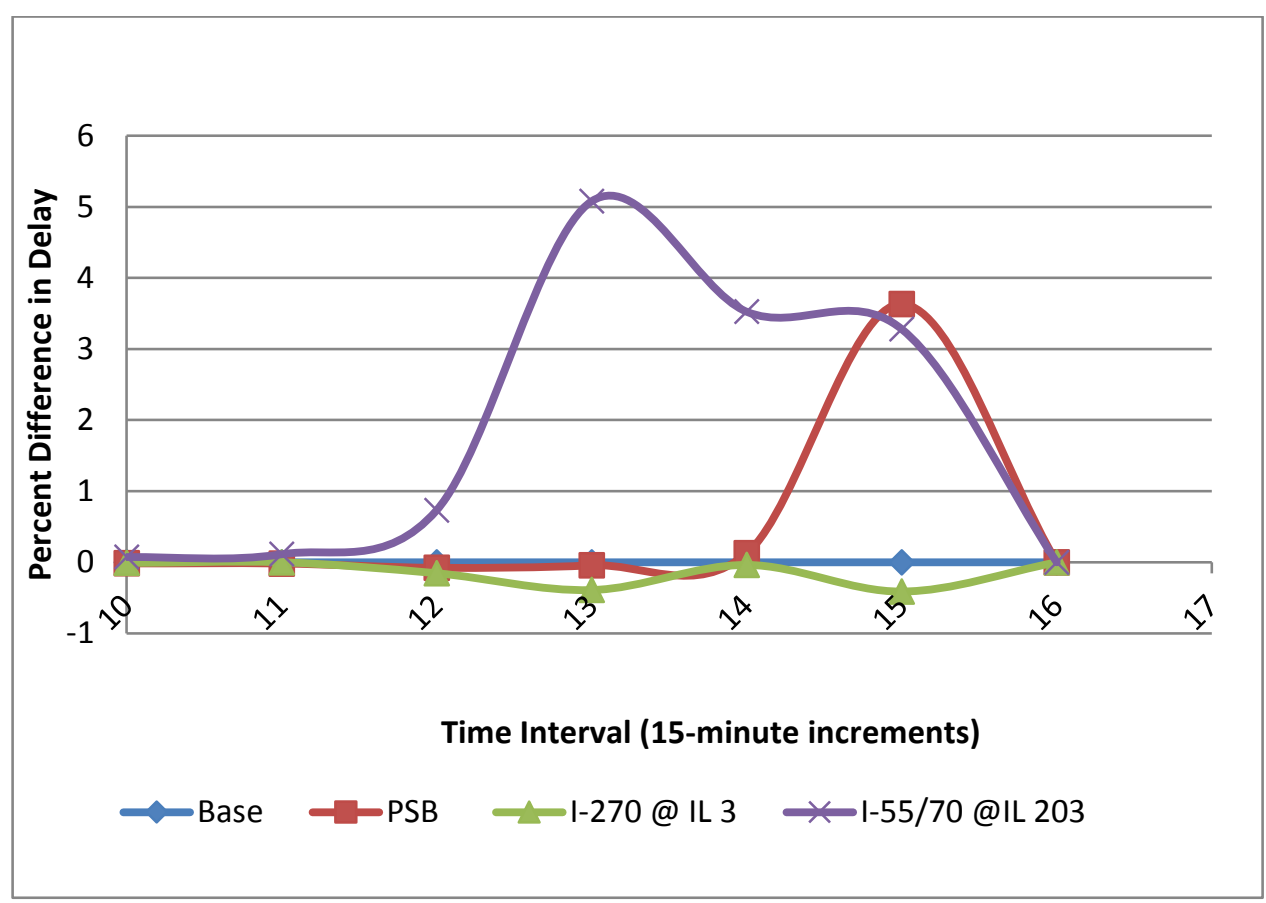

Figure 4: Normalized Average Network Delays

Estimates of impacts of traffic incident locations will help a comprehensive real-time traffic management during a traffic incident or during evacuation of at-risk populations by integrating with traffic management models. Findings of this research could be augmented with other decision support models that support real-time traffic management including traffic diversion during an evacuation $[38,39]$.

\section{Conclusions \& Recommendations}

The key contribution of this study was identifying the locations where traffic incidents can significantly increase durations during a no-notice evacuation. Previous related work did not all agree that minor traffic incidents would affect evacuation traffic operations. The findings of this simulation analysis revealed that incidents at locations downstream of bottlenecks did significantly increase the delay, agreeing with past research on evacuation traffic flow. The findings also support that incidents at locations upstream of bottlenecks or key merge points in the road network, did not cause any significant delay, concurring with past research in traffic flow and operations.

Thus, even minor traffic incidents have the potential to significantly increase the delay during evacuations, albeit not at every location. The findings herein underscore how traffic incident location plays an important role on evacuation duration. In this case study, the most-frequent locations of minor traffic incidents were upstream of a bottleneck and caused no significant impact to the evacuation operation. Even minor incidents downstream of this bottleneck did significantly increase traffic delays during an evacuation.

These findings can guide operations engineers to focus on traffic incident management resources during evacuations. For example, freeway service patrols such 
as Illinois' Emergency Patrol Vehicles (EPV) in the St. Louis metro area, can be staged near locations where traffic incidents will cause substantial increase of the evacuation duration, rather than towards locations where minor incidents occur more frequently. Though these patrols can minimize the detection times, they can also help clear minor incidents more efficiently, thereby decreasing the delay during the overall evacuation.

The findings of this study can contribute to both researchers and practitioners as well. Researchers can use the findings of this study to justify the inclusion of traffic incidents into demand modeling for evacuation scenarios. Practitioners can use the findings to strategically deploy the limited traffic incident-management resources available during an evacuation event.

Future research could evaluate characteristics of traffic incidents occurring during real-world no-notice evacuations. It would be useful to quantify the location of incidents during such events to improve the accuracy of future models; providing specific guidance during future evacuation planning efforts.

\section{Lessons Learned}

- Using traffic simulation provides valuable insight to the expected network performance during an evacuation.

- Vissim models could require unique calibration parameters to simulate driver behavior at merges and diverges realistically during evacuation events.

- Incidents should be considered when evaluating traffic conditions during evacuations.

- Even minor incidents could impact vehicle delay during evacuations if occurring downstream of bottle necks.

- Incidents upstream of bottle necks might not necessarily change delay during an evacuation.

- Identifying problematic areas will assist in better resources management and more efficient response during a no-notice evacuation.

- Incident responders along evacuation routes should be deployed at locations upstream of bottle necks.

\section{Acknowledgements}

The authors would like to thank Mr. Tom Korty of the Illinois Department of Transportation (IDOT) for his guidance and the Illinois Terrorism Taskforce for funding a portion of this study. Additional thanks are due to the East West Gateway Council of Governments and District Eight of IDOT. 


\section{References}

[1] Xuwei Chen, "Agent-Based Simulation of Evacuation Strategies under Different Road Network Structures," Department of Geography, Southwest Texas State University, Texas, 2003.

[2] Daiheng Ni, "Challenges and strategies of transportation modelling and simulation under extreme conditions.," International journal of emergency management, vol. 3, no. 4, 2006.

[3] W F Witzig and J K Shillenn, "Evaluation Of Protective Action Risks," Washington, D.C., 1987.

[4] S Wilson-Goure, N Houston, and A Van Easton, "Literature Search: Assessment of the State of the Practice and State of the Art in Evacuation Transportation Management," Washington, D.C., FHWA-HOP-08-015, 2006.

[5] A Collins, P Foytik, E Frydenlund, R M Robinson, and C A Jordan, "Investigating the impact of traffic incidents on large-scale emergency evacuation times using a generic incident model," in Transportation Research Board Annual Meeting Compendium of Papers, Washington, 2014.

[6] D J Fonseca, Y Lou, G P Moynihan, and S Gurupackiam, "Incident Occurrence Modeling during Hurricane Evacuation Events: The Case of Alabama's I-65 Corridor," Modelling and Simulation in Engineering, p. 6, 2013.

[7] L Dotson and J Jones, "Identification and Analysis of Factors Affecting Emergency Evacuations.," Albuquerque, NM, 2005.

[8] L J Dotson and J Jones , "Developement of Evacuation Time Estimate Studied for Nuclear Power Plants," Division of Preparedness and Response, U.S. Nuclear Regulatory Commission, Washington, DC, 2005.

[9] M Chen, L Chen, and E Miller-Hooks, "Traffic Signal Timing for Urban Evacuations," Journal of Urban Planning and Development, pp. 30-42, March 2007.

[10] S R Chen, C S Cai, and B Wolshon, "From Normal Operation to Evacuation: Single-Vehicle Safety under Adverse Weather, Topographic, and Operational Conditions," Natural Hazards Review, vol. 10, no. 2, pp. 68-76, 2009.

[11] KLD Associates, Inc., "Evacuation Time Estimates Technical Support Document: Pickering B Refurbishment for Continued Operation Envronmental Assessment," Pickering, Ontario, 2008.

[12] M Agarwal, T Maze, and R Souleyrette, "Impacts of Weather on Urban Freeway Traffic Flow Characteristics and Facility Capacity," in Mid-Continent Transportation Research Symposium, 2005.

[13] SAIC, "A Study of the Impact of Nine Transportation Management Projects on Hurricane Evacuation Preparedness," Oak Ridge, TN, DTFH61-96-C-00098, 2003.

[14] FHWA, "Evacuation Transportation Management," Washington, D.C., 2006.

[15] Aubery Samost. (2010) Mission 2010 New Orleans. [Online]. http://web.mit.edu/12.000/www/m2010/finalwebsite/katrina/evacuationplan.html

[16] Jennifer Peltz. (2013, May) NYC Evacuation Zones Will Be Expanded to Include Another 640,000 People. [Online]. http://www.huffingtonpost.com/3013/05/03/nyc-evacuation-zonesexpanded-disaster-sandy n $3210732 . \mathrm{html}$

[17] Charles E. Wallace, Annabelle Boyd, Jason Sergent, Anne Singleton, and Stephen Lockwood, "A Guide to Emergency Response Planning at State Transportation Agencies," Washington, D.C., 2010.

[18] Corene Matyas et al., "Risk perception and evacuation decisions of Florida tourists under hurricane threats: a stated preference analysis," Gainesville, FL, DOI 10.1007/s11069-011-9801-0, 2001.

[19] Miller DS, Rivera JD Burnside R, "The impact of information and risk perception on the hurricane evacuation decision-making of greater New Orleans residents," United Kingdom, Volume 27, Issue 6, 2007.

[20] Lindell MK and Perry RW, "Communicating environmental risk in multiethnic communities," 
Thousand Oaks, CA, Communicating Effectively in Multicultural Contexts: Volume 7, 2004.

[21] Lindell MK and Prater CS, "A hurricane evacuation management decision support system (EMDSS)," Gewerbestrasse, Switzerland, Volume 40, Issue 3, pp 627-634, 2007.

[22] American Highway User Alliance, "Emergency Evacuation Report Card," Washington, D.C., 2006.

[23] Y.-C. Chiu, H Zheng, J A Villalobos, W Peacock, and R Henk, "Evaluating Regional Contra-Flow and Phased Evacuation Strategies for Texas Using a Large-Scale Dynamic Traffic Simulation and Assignment Approach," Journal of Homeland Security and Emergency Management, vol. 5, no. 1, 2008.

[24] C Li and F Wang, "Emergency Evacuation Study for the Greater Jackson Area: Evacuation Traffic from New Orleans," Mississippi Departent of Transportation, Final Project Report 2011.

[25] M D Rossetti and Q Li, "Simulating Large-scale evacuation scenarios in commercial shopping districts - methodologies and case study," in Proceedings of the 2010 Winter Simulation Conference, 2010, pp. 3494-3505.

[26] R N Fries, M A Chowdhury, M Yongchang, and L Stephen, "Evaluation of different contraflow strategies for hurricane evacuation in Charleston, South Carolina," Transportation Planning and Technology, vol. 34, no. 2, pp. 139-154, 2011.

[27] Brandie Piper, "Senate votes to name I-70 bridge after Stan Musial," USA Today, June 2013. [Online]. http://www.usatoday.com/story/sports/mlb/cardinals/2013/06/27/senate-votes-to-name-i70-bridge-after-stan-musial/2466449/

[28] US Census Bureau. (2010) United States Census Bureau. [Online]. http://www.census.gov/population/www/cen2010/cph-t/cph-t-5.html

[29] A Pal, A Graettinger, and M H Triche, "Emergency Evacuation Modeling Based On Geographical Information System Data," , Washington, D.C., 2003.

[30] P M Murray and H S Mahmassani, "Model of Household Trip Chan Sequencing in an Emergency Evacuation," in 82nd Annual Meeting of the Transportation Research Board, Washington, D.C., 2003, p. 26.

[31] S Liu, P Murray-Tuite, and L Schweitzer, "Relocating Children in Daytime No-Notice Evacuations," Transportation Research Record: Journal of the Transportation Research Board, vol. 2234, pp. 79-88, 2011.

[32] Real-Time System Management Information Program 23 CFR Part 511, November 8, 2010.

[33] David Handford and Alex Rogers, "An agnet-based social forces model for driver evacuation behaviors," Springer, Regular 2012.

[34] J Hourdakis, P G Michalopoulos, and J Kottommannil, "A practical procedure for calibrating microscopic traffic simulation models," Transportation Research Record, vol. 1852, pp. 130-139, 2003.

[35] Y Ma, M Chowdhury, R Fries, and K Ozbay, "Harnessing the Power of Microscopic Simulation to Evaluate Freeway Service Patrols," Journal of Transportation Engineering, pp. 427-439, 2009.

[36] Monica Menendez and Carlos Daganzo, "Assessment of the Impact of Incidents Near Bottlenecks: Strategies to Reduce Delay," Transportation Research Record: Journal of the Transportation Research Board, no. 1867, pp. 53-59, 2004.

[37] S.M.M. Kahaki, Md. Jan Nordin, and Amir Hussein Ashtari, "Incident and Traffic-Bottleneck Detection Algorithm in High-Resolution Remote Sensing Imagery," ITB Journal, vol. 6, no. 2, pp. 151-170, 2012.

[38] P Bhavsar, M Chowdhury, A Sadek, W Sarasua, and J Ogle, "Decision Support System for Predicting Traffic Diversion Impact across Transportation Networks using Support Vector Regression," Transportation Research Record, vol. 2024, pp. 100-106, 2008.

[39] M Chowdhury, A Sadek, Y Ma, N Kanhere, and P Bhavsar, "Applications of Artificial Intelligence Paradigms to Decision Support in Real-time Traffic Management," Transportation 
International Journal of $x x x x x x$ Vol. $x$, No. $x, x x x x x, 20 x x$

Research Record, vol. 1968, pp. 92-98, 2006. 